\title{
De la propaganda franquista a la Marca España: 70 años de Radio Exterior de España.
}

\author{
Miguel Ángel OrTIZ SoBrino \\ Universidad Complutense de Madrid \\ maortiz@ucm.es
}

\begin{abstract}
Resumen:
En 2012, se ha cumplido el LXX aniversario de las emisiones internacionales de Radio Nacional de España que, desde 1977, se emiten bajo el indicativo de Radio Exterior de España. Aunque comenzaron como instrumento propagandístico de la dictadura franquista, la instauración en España de una Monarquía Parlamentaria, tras la muerte de Franco en 1975, propició un cambio de rumbo en la emisora. A partir de entonces, sus emisiones han servido para trasladar al mundo la nueva normalización democrática y los valores de España como país.
\end{abstract}

Palabras clave: Radio Exterior de España, emisiones internacionales, radios internacionales, propaganda, radiodifusión exterior, Marca España.

\section{From Franco's propaganda to the Brand Spain: 70 years of Spanish Foreign Radio.}

\begin{abstract}
:
In 2012, it was the LXX anniversary of the international emissions of the Spanish National Radio that, since 1977, have been issued under the name Spanish Foreign Radio. Although they started as an advertising instrument of the Franco dictatorship, the establishment of a Parliamentary Monarchy after Franco's dead, in 1975, supposed a change in the station. Right then, their emissions have served to export to the world the new democratic standards and values of Spain as a country.
\end{abstract}

Key words: Radio Exterior of Spain, international broadcasts, international radio, propaganda, foreign broadcasting, Spain mark.

\section{Referencia normalizada:}

Ortiz Sobrino, M. A. (2013) De la propaganda franquista a la Marca España: 70 años de Radio Exterior de España. Historia y Comunicación Social. Vol. 18 Nº Especial Octubre. Págs. 219-230

Sumario: 1.- Introducción: Marco contextual y estado de la cuestión 1.1.- Marco contextual: Radio Exterior de España, hoy. 1.2.- Un marco teórico para entender Radio Exterior de España en el contexto de las radios internacional. 2.- El nacimiento de la radiodifusión internacional española 2.1.- La propaganda del régimen franquista como epicentro de las emisiones internacionales de Radio Exterior de España. 3.- La transición democrática española cambia el rumbo de su radiodifusión exterior. 4.- Dos décadas para el cambio definitivo: 1992-2012. 5.- Conclusiones. 6. Referencias bibliográficas 


\section{Introducción: marco contextual y estado de la cuestión}

En 2012, se ha cumplido el LXX aniversario de Radio Exterior de España, la emisora pública que emite programas dirigidos a los ciudadanos de otros países y a los españoles que viven o trabajan en el extranjero. Sus primeras emisiones se remontan al año 1942, cuando se puso en marcha el Servicio de Lenguas Extranjeras de la radio estatal con el indicativo "Emisiones para el Exterior de Radio Nacional de España". Sin embargo, muerto Franco e iniciado el camino hacia la transición democrática española, la emisora empezó a transmitir con el indicativo actual de "Radio Exterior de España", a partir de 1977.

\subsection{Marco contextual: radio exterior de españa, hoy}

Radio Exterior de España es una de las seis cadenas de Radio Nacional de España, integrada en el grupo Radiotelevisión Española (RTVE). Se trata de la oferta de radio internacional promovida desde la radiotelevisión pública estatal en la que se emiten programas en español, portugués, francés, inglés, ruso, árabe, gallego, catalán y euskera.

El artículo 3 de la Ley de la Corporación RTVE, de 2006, recoge la misión de la radiotelevisión pública de producir y emitir programas de cobertura internacional que propicien la proyección hacia el exterior de las lenguas y la cultura española. De igual forma, este texto legal encomienda específicamente a la radio pública estatal la emisión de programas de servicio público, dirigidos a los ciudadanos españoles desplazados o residentes en el extranjero.

Desde su nacimiento, Radio Exterior de España ha coexistido con otras emisoras internacionales promovidas por diferentes países. Pero, frente a algunas de ellas que nacieron con una clara vocación de servicio, la emisora española estuvo marcada durante sus primeras cuatro décadas por el afán propagandístico del régimen dictatorial del General Franco. Sólo a partir de la muerte del dictador, en 1975, sus emisiones empezaron a discurrir por la senda democrática por la que caminaban muchas de las emisoras internacionales.

Como ha ocurrido con otras radios internacionales, hasta no hace mucho sus emisiones utilizaron la onda corta, preferentemente, como vía de transmisión. Sin embargo, hoy sus programas pueden escucharse -también- a través de Internet, por vía satélite y mediante diferentes aplicaciones para telefonía móvil.

1.2 Un marco teórico para entender radio exterior de españa en el contexto de las radios internacionales

El fenómeno de la radiodifusión exterior de los diferentes países ha sido, para muchos investigadores, objeto de análisis y reflexión. En unos casos, este tipo de radio ha sido estudiada desde una perspectiva general (Wood, 1992) y, en otros, como arma política (Hale, 1979). Igualmente, el sistema de las radios internacionales ha 
sido analizado por diferentes investigadores, como Head (1985) y Rodríguez (2009), mientras que Jiménez y Arasa (2012), por ejemplo, se han ocupado de los contenidos de su programación.

En el caso español, el poder propagandístico de la radiodifusión exterior española ha sido puesto de manifiesto por muchos historiadores de la comunicación, como Arias Ruiz (1973), Munsó Cabús (1988) y Cervera (2005), entre otros. De igual forma, Martín Caro (2000) y Calvo (2006) han abordado el papel de la radio internacional en la convergencia multimedia y en relación con el posicionamiento de la imagen de España en el exterior. De la literatura científica existente sobre las emisiones internacionales de la radio pública española destacan, especialmente, cuatro investigaciones realizadas en la década de los 90 por profesionales que -en aquel momento- prestaban servicio en Radio Nacional de España: Gómez Fernández (1993), Montes (1998), Ortega Benito (1997) y Martín Caro (2000). Más recientemente, los hermanos Martínez Arias (2013) han reflexionado sobre el impacto de la globalización y las nuevas tecnologías en Radio Exterior de España.

El recorrido por esta literatura científica y la contextualización histórica de esta cadena de radio permiten valorar la influencia del sistema político español en las emisiones internacionales de la radio pública, y en qué medida sus contenidos se han correspondido con los intereses políticos nacionales de cada momento. Para contextualizar los resultados que se presentan en este artículo se ha partido de una técnica documental, así como de la lectura de algunas obras y documentos que han permitido elaborar un marco teórico sobre las emisiones internacionales de la radio pública española. A partir de ahí, se ha extraído una serie de conclusiones en torno a su influencia política y evolución.

\section{El nacimiento de la radiodifusión internacional española}

El documento "50 aniversario de Radio Exterior de España", editado por el Servicio de Publicaciones de RTVE (1992), sitúa en el día 15 de marzo de 1942 el comienzo de las primeras emisiones internacionales de Radio Nacional de España hacia Europa y América. Para referenciar la fecha, el documento recoge el siguiente anexo de la revista "Radio Nacional", del 8 de mayo de aquel año, en el que se anunciaban los primeros programas y sus horarios de emisión:

"La Vicesecretaría de Educación Popular ha organizado unas nuevas emisiones radiofónicas que inaugurará Radio Nacional de España el domingo 15 de los corrientes. Una de ellas para Europa, de siete a ocho de la tarde, y otra para América, de una a dos de la madrugada, hora española. Estas emisiones se realizarán en Onda Corta de 30,42 metros $9860 \mathrm{Khz}$. Intervendrán relevantes personalidades de las Artes, de las Ciencias y de las Letras, y la parte artística será también de gran altura. Con estas nuevas emisiones que se realizarán a diario, Radio Nacional de España amplía considerablemente su programación y la prestigia, llevando su voz a Centro Europa y América." 
Estas primeras emisiones fueron realizadas diariamente -excepto los domingos- a través de la Sociedad R.E.D.E.R.A. (Red Española de Radiodifusión). Para ello, se utilizaron la emisora nacional de onda corta de Aranjuez (30,42 metros $9680 \mathrm{Khz}$.), la estación de radio local de Madrid (207,3 metros 1447 Khz.) y Radio España (371,3 metros y $804 \mathrm{Khz}$.). Sus primeros programas fueron emitidos en castellano, inglés y francés, pero unos años más tarde se incorporaron -también- programas en alemán, italiano, portugués y árabe.

Aunque las primeras emisiones se sitúan en 1942, lo cierto es que Franco ya tomó conciencia de la importancia de la radio como arma propagandística y de información durante la Guerra Civil, entre 1936 y 1939. Sin embargo, la situación de guerra del país había dado como resultado una precaria situación económica y un desarme tecnológico absoluto. Por este motivo, para desarrollar las emisiones de radio en onda corta y onda media, se decidió buscar la colaboración de países que apoyaban el levantamiento militar español: en concreto, Alemania e Italia.

Son varios los investigadores españoles que han recogido estos primeros pasos de la colaboración hispano-alemana para la implementación de emisiones radiofónicas (Ortega Benito, 1977 y Montes, 1998). El investigador Francisco José Montes (1998) menciona como primeros movimientos, en este sentido, las conversaciones realizadas entre los delegados del Ministerio de Comunicaciones alemán, cuya representación ostentaba Günter Flanes, y los responsables de la Sección Técnica de la Delegación del Estado para la Prensa y Propaganda en España. Las conversaciones y los términos de colaboración fueron plasmados en el convenio firmado en Burgos, el 25 de marzo de 1938, entre el entonces Ministro del Interior, Ramón Serrano Súñer, y el jefe de la delegación alemana. En virtud de ese convenio, Alemania vendería equipo y material técnico a España para la instalación de dos emisoras de radio que sirvieran para la "lucha contra el bolchevismo mundial". Los puntos fundamentales del convenio, según Montes, se centraban en los siguientes aspectos: por un lado, España encargaba a Alemania el suministro de una emisora de onda media y otra de onda corta; por otro, Alemania crearía la "Sección Garnot", con técnicos alemanes especializados que residirían en la embajada alemana; finalmente, Alemania sería la encargada de seleccionar las empresas de aquel país que suministrarían la tecnología necesaria (Montes, 1998:158-159). De acuerdo al convenio, el Gobierno español designaría el emplazamiento de las emisoras y correría con los gastos del personal alemán que se quedara en España para asesorar a los técnicos españoles.

Francisco José Montes sostiene que en el comienzo oficial de las emisiones de Radio Nacional de España para Europa, en el año 1942, había tres programaciones diferentes: una emisión en francés aderezada con música española, titulada "La voz de España para Francia", que se emitía de 19,00 a 19,15 horas; una segunda emisión en inglés, con información y música, de 19,15 a 19,30, titulada "La voz de España para Inglaterra"; y por último, una emisión denominada "La voz de España para la División Azul”, emitida entre las 19,30 y las 20,00 horas. 
2.1. La propaganda del régimen franquista como epicentro de las emisiones internacionales de radio exterior de españa

Hay cierta unanimidad entre los investigadores al afirmar que los orígenes de las radios internacionales estuvieron marcados, en muchos casos, por una cierta vocación propagandística de los países que las promovieron. Así lo han constatado diferentes investigadores, como Gómez Fernández (1994), Pizarroso (1998) y Balsebre (2002). Pero, a medida que fueron desapareciendo las condiciones político-militares que propiciaron su aparición, esas emisoras perdieron su primera vocación para ir dando paso a fines relacionados con la imagen y las relaciones internacionales de los países patrocinadores.

Lo mismo sucedió en el caso español (Ortega, 1997 y Cervera, 2005). Frente a otras experiencias coetáneas de radios internacionales europeas -como el Servicio Mundial de la B.B.C., Radio France Internacional o la Deutsche Wele- las emisiones radiofónicas de España hacia el exterior se iniciaron con el propósito de presentar ante la comunidad internacional una imagen amable de la dictadura franquista, reservando su beligerancia principalmente a los contenidos de los programas dirigidos a los países del Este de Europa que estaban bajo la órbita socialista.

No podía ser de otra manera si se tiene en cuenta que la emisora promotora de esas primeras emisiones fue una radio fundada por el régimen militar salido de la Guerra Civil Española (1936-1939). Cabe recordar que seis meses después del alzamiento militar del General Franco en Julio de 1936, el locutor Fernando Fernández de Córdoba dio comienzo a las primeras emisiones de Radio Nacional de España, desde Salamanca, en las que los discursos radiofónicos de Franco, los partes de guerra y las marchas militares fueron sus contenidos prioritarios . Finalizada la Guerra Civil, con la victoria franquista, Radio Nacional de España pasó a depender de los organismos oficiales que controlaban la prensa y la propaganda del nuevo régimen: inicialmente, de la Vicesecretaría de Educación Popular; posteriormente, en 1945, del Ministerio de Educación Nacional; y, a partir de 1951, del Ministerio de Información y Turismo (Gómez García y Martín Quevedo, 2012; Bermejo Sánchez, 1991).

Se cuenta en la revista ICONO 14 como esos comienzos de Radio Nacional de España, en el seno de uno de los bandos contendientes en la Guerra Civil, determinaron su politización desde el primer momento. Así lo manifiesta Munsó Cabús (1988) cuando afirma que Radio Nacional de España nació con una finalidad propagandística al servicio de la causa defendida por el General Franco (Ortiz Sobrino, 2012: 338 y Ortiz Sobrino, 1999). Fueron esos orígenes vinculados a la dictadura militar los que marcaron el carácter propagandístico de estos primeros años de emisiones internacionales de lo que hoy se conoce como Radio Exterior de España.

En el periodo comprendido entre 1942 y 1955, los contenidos de los programas internacionales manifestaban esa clara orientación propagandística y de apología del régimen franquista. Cuenta Cervera (2005) que el General Franco, que había ganado la contienda civil española cinco años antes, contemplaba con preocupación 
el panorama derivado de un inminente conflicto bélico en Europa: la Segunda Guerra Mundial. El franquismo había apostado por el eje liderado por la Alemania nazi, que finalmente sería el bando derrotado. El desarrollo de la guerra y postguerra se auguraba como un escenario hostil hacia la dictadura española, como así fue. Finalizada la Segunda Guerra Mundial se abrió -efectivamente- un periodo de incertidumbre marcado por la animadversión de los vencedores de la contienda mundial hacia el Gobierno de Madrid. Por esa razón, las emisiones durante 1944 y 1945 se caracterizarían fundamentalmente por su agresividad verbal y, en buena medida, por su contundencia en los adjetivos dirigidos a todos los considerados enemigos del régimen. Según Cervera (2005: 181-197), entre 1946 y 1951, la política de programación de las emisiones se centraba en la defensa del régimen y ataques al comunismo.

A partir de 1952 llama la atención la profusión de noticias sobre los Estados Unidos en la emisora, con motivo de la mejora de las relaciones bilaterales. Con la entrada de España en Naciones Unidas, en 1955, la acción dialéctica de las emisiones para el exterior empezaron a suavizarse, perdiendo intensidad propagandística. No obstante, ya en esa década, la producción y emisión de programas para el exterior llevados a acabo por la radio pública había crecido considerablemente. Autores, como Gómez García y Martín Quevedo (2012:1-19) han contabilizado hasta veinte "Diarios hablados", en 1947: diez de ellos para España, seis para Europa (Inglaterra, Francia, Italia, Alemania, Portugal y Rusia), dos para África y otros dos para América.

Comenta Ortega Benito (1998) que, en esta década de los 50, los programas en Onda Corta de Radio Nacional de España se clasificaban en tres grupos: las emisiones para los países del telón de acero o de bambú, las emisiones para el mundo occidental y los programas para el mundo árabe. En el primer grupo, las emisiones iban dirigidas concretamente a China, Ucrania, Letonia, Estonia, Lituania, Rusia, Bielorrusia, Albania, Croacia, Bulgaria, Eslovaquia, Hungría, Rumania y Polonia. Para el mundo occidental se transmitían seis programaciones diferentes: la inglesa, la francesa, la alemana, la italiana, la brasileña y una especial para los Estados Unidos y Canadá. Y, finalmente, el tercer grupo de emisiones árabes, en su doble vertiente: una general, dirigida a los países árabes y otra orientada especialmente a Marruecos, como pueblo amigo al otro lado del Estrecho. Sin embargo, el gran salto cualitativo de la radiodifusión exterior se produciría en 1971, con la inauguración del Centro Emisor de Onda Corta en Noblezas (Toledo).

La tutela política de la radio por parte del régimen franquista, a la que se ha venido aludiendo, se mantendría prácticamente hasta la promulgación de la Carta Magna Española, en 1978. A partir de aquel momento, la orientación de la emisora cambió sustancialmente. 


\section{La transición democrática española cambia el rumbo de la radiodifusión exte- rior}

El fallecimiento del General Franco, en 1975, y la instauración en España de una Monarquía Parlamentaria propiciaron un cambio de orientación en estas emisiones que -hasta 1977- se transmitieron bajo el indicativo "Emisiones para el exterior de Radio Nacional de España". A partir de entonces, la vocación propagandística perdió peso para dar paso paulatinamente a contenidos dirigidos a otros target y programas de interés para el Estado español. La normalización democrática del país y su nueva organización territorial fueron algunos de los ejes vertebradores de su programación, en la que, a partir de 1985, se podía escuchar un programa informativo con crónicas en euskera, catalán y gallego.

García González (2006) ha escrito que, desde el final de la dictadura franquista hasta la llegada del Partido Socialista Obrero Español al poder en 1982, la radio pública fue adquiriendo un carácter marcadamente informativo que le permitió desempeñar un protagonismo esencial para el cambio político y la consolidación del modelo democrático español. Ya en los primeros años del Gobierno socialista, las emisiones internacionales de Radio Nacional de España mostraban claramente el cambio de rumbo político. Así, en la Memoria de RNE de 1984, se ponía de manifiesto que, a través de Radio Exterior de España, se intentaba ofrecer la imagen de un país nuevo, en lo político, lo económico y lo social (RTVE, 1984).

Martínez Arias (2013: 487-504) se hace eco del inicio de las emisiones en catalán, gallego y euskera a lo largo de esa década de los 80 y en qué medida se produjeron, también, cambios en las emisiones de lenguas extranjeras. En este sentido, hace referencia a la desaparición de las emisiones en italiano y alemán, y la incorporación de otras nuevas en ruso y sefardí. No obstante, frente a lo manifestado por Martínez Arias, en los datos de la Memoria de Radio Nacional de España de 2002 aparece en la oferta de contenidos de la emisora una programación en alemán (RTVE, 2002).

Diez años después del triunfo socialista en las Elecciones Generales de 1982, y con motivo de la celebración de las Olimpiadas en Barcelona y la celebración en Sevilla de la Expo 92, el papel de Radio Exterior de España en la proyección de la imagen del país se incrementó, incorporando a su parrilla de programación espacios específicos sobre estos dos eventos. En ese año, sus emisiones salieron reforzadas en el continente americano tras inaugurarse su primer centro emisor de onda corta en Costa Rica, que permitió llevar sus programas a una zona que abarca desde el sur de los Estados Unidos hasta Brasil (RTVE, 1992).

\section{Dos décadas para el cambio definitivo: 1992-2012}

En 1992, con motivo de la celebración del medio siglo de emisiones de Radio Exterior de España, Jordi García Candau -en aquel momento Director General de Radio Televisión Española- presentaba a la emisora como portavoz ante el mundo de 
una España joven, dinámica, libre y democrática. Puede decirse que, desde entonces hasta hoy, ha sido el periodo en el que este canal radiofónico se ha identificado más con la política exterior de España, independientemente de la orientación política de los gobernantes españoles.

Desde su triunfo electoral en las Elecciones Generales de 1982, los diferentes Gobiernos del Partido Socialista Obrero Español adecuaron los objetivos de Radio Exterior de España a la nueva imagen del país y su senda democrática. También con la llegada del primer Gobiernos del Partido Popular, tras su victoria en las Elecciones Generales de 1996, Radio Exterior de España se afianzó como vehículo de proyección de la imagen de España en el extranjero. Hasta tal punto que, en los primeros años de la primera década del milenio, se contabilizaban emisiones en diez idiomas diferentes: español, inglés, francés, alemán, árabe, ruso, catalán, vasco, gallego y sefardí. Durante este periodo la audiencia de la emisora se consolidó, llegando a cifrarse en 80 millones de personas, en 2002 (RTVE, 2002).

En 2004, el Partido Socialista Obrero Español volvió a gobernar tras ganar las Elecciones Generales de ese año. Durante esta nueva etapa de gobierno, entre 2004 y 2011, se produjeron algunas iniciativas de amplia repercusión para la radio pública estatal y, por tanto, para Radio Exterior de España. Especialmente, la Ley de Creación de la Corporación de la Radio y la Televisión estatal que apostó por una radiotelevisión pública fuerte (Jivkova, 2011). En este periodo, se promovieron iniciativas encaminadas a la promoción del idioma y la cultura española en el mundo, en las que participó Radio Exterior de España a través de acuerdos institucionales con organismos públicos -como el Instituto Cervantes- y la promoción de intercambios con diferentes emisoras internacionales: Radio Internacional de China y Radio Nederland, entre otras (RTVE, 2011).

Como ya se ha avanzado, en las dos últimas décadas, los contenidos de Radio Exterior de España han estado en consonancia con la política llevada a cabo desde el Ministerio de Asuntos Exteriores. Desde esa perspectiva puede encuadrarse la inclusión de una emisión sefardí en su parrilla de programación o la más recientemente vinculación de esta cadena a la acción diplomática del Ministerio de Asuntos Exteriores. Juan María Calvo (2006) destaca la labor de la emisora en materia de cooperación internacional, llevada a cabo a través de convenios con más de seiscientas emisoras en español repartidas por todo el mundo. De igual forma, como medio de difusión de la "Marca España", alude Calvo la aportación de Radio Exterior de España en la promoción del idioma y la cultura española, a través de programas como "Un idioma sin fronteras" (Calvo, 2006: 2-4).

Coincidiendo con su LXX aniversario, en 2012, Radio Exterior de España se ha convertido en un elemento de transmisión de las fortalezas de nuestro país en los cinco continentes, bajo el lema "Radio Exterior, Marca España en el mundo" (RTVE, 2012). En este sentido, en el mes de noviembre de ese año se puso en marcha una nueva programación con contenidos relacionados con la realidad española del siglo 
XXI, en todos los campos: conocimiento economía, sociedad, ciencia y técnica, y diversidad cultural y lingüística.

Ahora Radio Exterior de España es una referencia entre las radios internacionales del Viejo Continente. Sostiene Jones (2006) que -como consecuencia de las transformaciones internas en España derivadas de su democratización política y su modernización cultural y tecnológica, desde la muerte de Franco hasta hoy- el sistema comunicativo y cultural español no difiere demasiado del de sus homólogos de la actual Unión Europea. En este sentido, Radio Exterior de España es, hoy, una emisora homologable con otras de amplia trayectoria democrática, como las emisiones internacionales de la BBC, en el Reino Unido. De hecho, Radio Exterior ha estado presente, en los últimos años, en los más importantes acontecimientos políticos, económicos, deportivos y culturales poniéndose así de manifiesto, y en la práctica, el servicio público que caracteriza a este canal internacional (RTVE, 2011).

Pero, ¿es la audiencia de Radio Exterior de España el público objetivo de la "Marca España"?. La respuesta no es fácil porque, como sostiene Martínez Arias (2012), la ausencia de las herramientas necesarias -tanto tecnológicas como financieras- para implementar un procedimiento empírico de medición de su audiencia, hace imposible una precisión rigurosa, quedando tan solo una estimación, seguramente subjetiva y/o interesada.

\section{Conclusiones}

Los inicios de las emisiones de Radio Exterior de España, en 1942, estuvieron marcados por el régimen militar de la dictadura franquista. Sus primeros años de existencia tuvieron un claro carácter propagandístico que fue utilizado por el régimen franquista para hacer apología del régimen y atacar al comunismo. Sin embargo, a partir de 1952, las emisiones empezaron a perder la beligerancia inicial y se observó un cierto acercamiento a Estados Unidos, incluyendo la presencia de más contenidos relacionados con aquel país, coincidiendo con la mejora de las relaciones bilaterales.

La entrada de España en Naciones Unidas, en 1955, marcó un antes y un después en la pérdida de intensidad propagandística de las emisiones. El fallecimiento del General Franco, en 1975, y la instauración en España de una Monarquía Parlamentaria propiciaron un cambio de orientación en estas emisiones que -hasta 1978- emitieron bajo el indicativo "Emisiones para el exterior de Radio Nacional de España".

Con la llegada de la transición democrática, Radio Exterior de España cambió definitivamente su orientación propagandística para transformase en un vehículo de comunicación para transmitir al resto del mundo la normalización democrática del país, la realidad de su nueva organización territorial y una imagen de sociedad con una clara apuesta por su integración en Europa. Una orientación nueva que ha sido respaldada tanto por los Gobiernos del Partido Socialista Obrero Español como por los del Partido Popular, a lo largo de estos años. En 2013, la emisora se ha convertido 
en uno de los instrumentos fundamentales para promover la imagen del país, sus idiomas, su cultura y sus valores, a través de lo que se ha venido a denominar como "Marca España".

\section{Referencias bibliográficas}

ARIAS RUIZ, A. (1973). 50 de radiodifusión en España. Madrid. Ministerio de Información y Turismo.

BERMEJO SÁNCHEZ, BENITO (1991). La vicesecretaría de Educación Popular (1941-1945): un "ministerio" de propaganda en manos de Falange. En Espacio, tiempo y forma, S.V., $H^{a}$ Contemporánea, no 4. Págs. 73-96.

BALSEBRE, A. (2002). Historia de la Radio en España. 2 Vols. Barcelona, Cátedra.

CALVO, J. M. (2006). Una herramienta infrautilizada: los medios de comunicación estatales en la proyección exterior. En Análisis de Real Instituto Elcano, $\mathrm{n}^{\mathrm{o}} 47$. 2006. Págs. 1-9

CERVERA GIL, J. (2005).Contra “el enemigo exterior”.Las emisiones de Radio Nacional de España en francés (1945-1953). En Comunicación y Hombre. Págs. 181-198

GARCÍA GONZÁLEZ, A. (2006). La Radio en la democracia (1982-2005). En ARROYO Y ROEL (edt.) (2006). Los medios de comunicación en la democracia (1982-2005).Madrid. Fragua.

GÓMEZ FERNÁNDEZ, P. (1994). La radio española para el exterior: Estructura y funciones de la acción española en el marco de la radiodifusión internacional. Tesis doctoral. Madrid. UCM.

GÓMEZ GARCÍA, S. y MARTIN QUEVEDO, J. (2012). Del yugo a la cruz. Radio Nacional de España: una radio en transición. (1945-1951). En Área Abierta, no 33.Pág. 1-19. http://dx.doi.org/10.5209/rev_ARAB.2012.v33.4055.

HALE, J. (1979). La radio como arma política. Barcelona. Gustavo Gili.

HEAD, S. (1985). World broadcasting systems. A comparative analysis. Belmont. Wadsworth Publisher Co.

JONES, D. (2006).La comunicación en España 30 años después de Franco (19752005). En revista Comunicación y Pluralismo.

JIVKOVA-SEMOVA, D. (2011). RTVE sin publicidad: un modelo de financiación en estado de emergencia. En revista Vivat Academia., nº116. Pág. 75-91.

MARTIN CARO, MIGUEL ANGEL (2000). La radio del siglo XXI. Un servicio público en la economía global. Madrid. Ed. Fragua.

MARTINEZ ARIAS, S. y MARTINEZ ARIAS, A. (2013).Evolución de la radio global y competencia en Internet. El caso de Radio Exterior de España. En Estudios sobre el Mensaje Periodístico, Vol. 19.Pág.487-504,1. DOI http://dx.doi. org/10.5209/rev_ESMP.2013.v19.n1.42534.

MONTES FERNÁN̄DEZ, F. J. (1998). Los orígenes de la radiodifusión exterior. Madrid. Ed. Complutense

MUNSÓ CABÚS, JUAN (1988). Escrito en el aires. Madrid. Servicio Publicaciones de RTVE. 
MURELAGA IBARRA, J. (2009) .Historia contextualizada de la radio española del franquismo (1940-1960). En Historia y Comunicación Social, vol. 14.

ORTEGA BENITO, R. (1977). Las radios internacionales y su relación con la audiencia. Tesis doctoral. Madrid. UCM.

ORTIZ SOBRINO, M. A. (1999). El marco de referencia para la fusión entre Radio Nacional de España y Radiocadena Española. En Revista SEECI, nº 3.Marzo. Pág. $32-40$.

ORTIZ SOBRINO, M. A. (2012). Evolución del modelo de financiación de Radio 5.Del Estatuto de radio y televisión de 1980 a la Ley General de Comunicación Audiovisual de 2010.En ICONO 14. Pág. 383-402.

PEÑA, P. y ARASA, D. (2012). Radio Vaticana, "La voz del Papa en el mundo" cumple 80 años (1931-2011).Análisis del programa en español. En ICONO 14, vol. $10, \mathrm{n}^{\circ}$ 2. Pág. 206-227.

PIZARROSO QUINTERO, A. (1998). Información y propaganda norteamericana en España durante las segunda Guerra Mundial: la radio. En Complutense de Historia de América. Pág. 223-246.

RODRIGUEZ, C.A. (2009). La radiodifusión internacional ante la convergencia digital. Futuro, realidades e imaginaciones. En Signo y Pensamiento, vol. 28 nº 54. Pág.377-380.

WOOD, J. (1992). History of internacional broadcasting.Londres. Peter Peregrinus Ltd.

Otros documentos.

RTVE (1992). 50 Aniversario de Radio Exterior de España”. Madrid. Servicio Publicaciones de RTVE.

RTVE (1984). Anuario.

RTVE (1992). Memoria

RTVE (2002). Informe Anual sobre el Cumplimiento de la Función de Servicio Público del Grupo RadioTelevisión Española.

RTVE (2011).Memoria sobre el cumplimiento de la Función de Servicio Público. RTVE (2012). Memoria sobre el cumplimiento de la Función de Servicio Público.

\section{El autor:}

Miguel Ángel Ortiz Sobrino es Doctor en Ciencias de la Información por la UCM. Licenciado en Periodismo y en Ciencias de la Imagen Visual y Auditiva. Es Master Oficial en Humanidades por la Universidad Francisco de Vitoria y Diplomado en Investigación de Medios por A.I.M.C. Imparte docencia en el área de Empresa Informativa en la UCM y es Delegado para Medialab/Inforadio de la Facultad de Ciencias de la Información de la misma Universidad. Su trayectoria profesional ha estado vinculada a RTVE. Desde 1977, ha desempeñado, entre otros, los cargos de Jefe de 
Programas de Radio 5, Subdirector de Emisoras Territoriales de RNE y Subdirector de Planificación de Programas de RNE. Entre el año 2000 y 2009 ha dirigido el Instituto Oficial de Radio y Televisión. Es autor de más de 40 publicaciones y artículos relacionados con el ámbito de la comunicación 